\title{
Distribution and feeding of blue whiting Micromesistius poutassou larvae in relation to different water masses in the Porcupine Bank area, west of Ireland
}

\author{
Nicola Hillgruber ${ }^{1, *}$, Matthias Kloppmann ${ }^{2}$ \\ ${ }^{1}$ Biologische Anstalt Helgoland in der Stiftung Alfred-Wegener-Institut für Polar- und Meeresforschung, Notkestrasse 31, \\ 22607 Hamburg, Germany \\ ${ }^{2}$ Institut für Hydrobiologie und Fischereiwissenschaft, Universität Hamburg, Olbersweg 24, 22767 Hamburg, Germany
}

\begin{abstract}
In March/April 1994 a hydrographic and ichthyoplankton survey was conducted in the area of Porcupine Bank, west of Ireland, to study the distribution and feeding of blue whiting larvae. The Porcupine Bank area was characterized by 2 distinguishable water masses separated by a thermal front: (1) the warm and saline waters of the secondary shelf edge current (sSEC) and (2) the cooler and less saline waters above Porcupine Bank associated with an anticyclonic circulation. Highest concentrations of recently hatched larvae $<4.0 \mathrm{~mm}$ standard length (SL) occurred in waters of the sSEC, while larvae $>4.0 \mathrm{~mm}$ SL were more abundant in the cool waters above Porcupine Bank and larvae $>5.0 \mathrm{~mm}$ SL were exclusively found above the bank. Copepod nauplii density was extremely low, with an overall mean density of $5.21^{-1}$ Nauplii were most abundant in the water of the sSEC. However, proportionally more large calanoid nauplii were observed above Porcupine Bank. The diet of blue whiting larvae also varied among water masses, with larvae having higher feeding incidences and numerical feeding intensities in the 5 SEC but significantly higher feeding intensities by weight and, thus, a higher energetic gain in the waters above the bank. These contrasts resulted from differences in the composition of the larval diet. Larvae in the sSEC preyed heavily on tintinnids and small cyclopoid nauplii, while larvae above Porcupine Bank also ingested large calanoid nauplii. In addition, blue whiting larvae had different selectivity patterns depending on the foraging environment, with larvae retained above Porcupine Bank selecting strongly for calanoid nauplii, which were never selected for by larvae in the sSEC. Instead those larvae demonstrated a preference for smaller cyclopoid nauplii. In summary, we conclude that in 1994 blue whiting larvae benefited from being retained above Porcupine Bank not only by maintaining a close horizontal distribution but also by utilizing the more favorable feeding environment above the bank.
\end{abstract}

KEY WORDS: Blue whiting larvae - Distribution · Diet $\cdot$ Feeding success $\cdot$ Prey selection $\cdot$ Retention

\section{INTRODUCTION}

While there are indications that inter-annual variation in recruitment strength of marine fish stocks arises from events occurring during the first year of life (Bailey \& Spring 1992), there is an ongoing controversy about factors and processes that might be responsible for recruitment success or failure. Even though there is agreement that survival of early life stages is deter-

·E-mail: nhillgruber@compuserve.com mined by several interacting factors, the impact of each is still unresolved. Limited food supply for firstfeeding larvae might result in increased mortality rates and thus lower recruitment (Houde 1987). However, the absolute stock abundance might also be dependent upon stable oceanographic retention areas that ensure population integrity by limiting larval dispersion (Iles \& Sinclair 1982). In a recent model-based approach Werner et al. (1996) simultaneously examined food limitation and retention of cod Gadus morhua and haddock Melanogrammus aeglefinus larvae on Georges 
Bank and concluded that in addition to being retained, larvae also experienced more favorable feeding conditions. Similarly, McLaren et al. (1997) concluded that larval cod G. morhua experienced highest feeding success and lowest displacement in the center of the Western Bank gyre. Thus, regions of retention might not only serve to maintain the genetic integrity of a given stock, but also provide enhanced feeding conditions for marine fish larvae.

Blue whiting Micromesistius poutassou is a predominantly pelagic species, which ranges along the western European shelf edge from Norway to southern Portugal. Its major spawning area is located to the west of the British Isles (Bailey 1982), with centers of spawning activity occurring in March and April above Rockall Bank, Porcupine Bank and in the Celtic Sea (Bainbridge \& Cooper 1973). Blue whiting spawn at depths of 300 to $600 \mathrm{~m}$ and larvae hatch there, ascending into the upper $100 \mathrm{~m}$ of the water column to initiate feeding (Coombs et al. 1981). Kloppmann et al. (1999) concluded that an anticyclonic circulation, i.e. Taylor column, above Porcupine Bank and the Rockall Gyre in the Rockall Trough, might facilitate the segregation of 2 larval populations. Taylor (1917) and Proudman (1916) were the first to theoretically describe the mechanism underlying the Taylor column phenomenon. Briefly, when a water body is advected towards a subsurface obstacle the upward deflection of the flow results in an anticyclonic (clockwise on the Northern Hemisphere) circulation above that obstacle with increasing velocity towards the bottom. This circulation cell remains stationary and is called a Taylor column. For the significance of Taylor columns in recruitment of fish populations see Bakun (1996).

However, the separation into 2 larval blue whiting populations appears to be incomplete, as Porcupine
Bank larvae could be expatriated by the secondary shelf edge current (sSEC) while ascending to surface waters. Therefore, the sSEC and the Porcupine Bank Taylor column provide 2 potential rearing environments for blue whiting larvae. Blue whiting larvae might thus experience very differing prey environments upon reaching surface waters.

In the present study we test the hypothesis that feeding of blue whiting larvae differs between 2 distinguishable water masses. In particular, we describe the rearing habitats for blue whiting larvae and compare prey environments and feeding success of first-feeding larvae in the waters of the SSEC and above Porcupine Bank. Furthermore, we attempt to determine whether retention areas, in addition to maintaining larval distribution, might provide better biotic conditions for firstfeeding blue whiting larvae.

\section{MATERIAL AND METHODS}

Field site and methods. Data for the study were collected on board the German RV 'Heincke' during a cruise to the area of Porcupine Bank and Porcupine Seabight, west of Ireland. In March/April 1994, a station grid located over Porcupine Bank was sampled targeting larval blue whiting. In order to evaluate the feeding environment and diet of larval blue whiting, a sub-sample of 13 stations on 2 transects ( $C$ and D) was chosen which included both the water masses of the sSEC and above Porcupine Bank (Fig. 1, Table 1). Sampling was carried out during both day and night.

Ichthyoplankton were collected over 9 depth intervals to a depth of $650 \mathrm{~m}$, using a multiple opening-closing net (MCN). The $\mathrm{MCN}$ had a mouth opening of $0.25 \mathrm{~m}^{2}$ and was equipped with $150 \mu \mathrm{m}$ mesh nets to

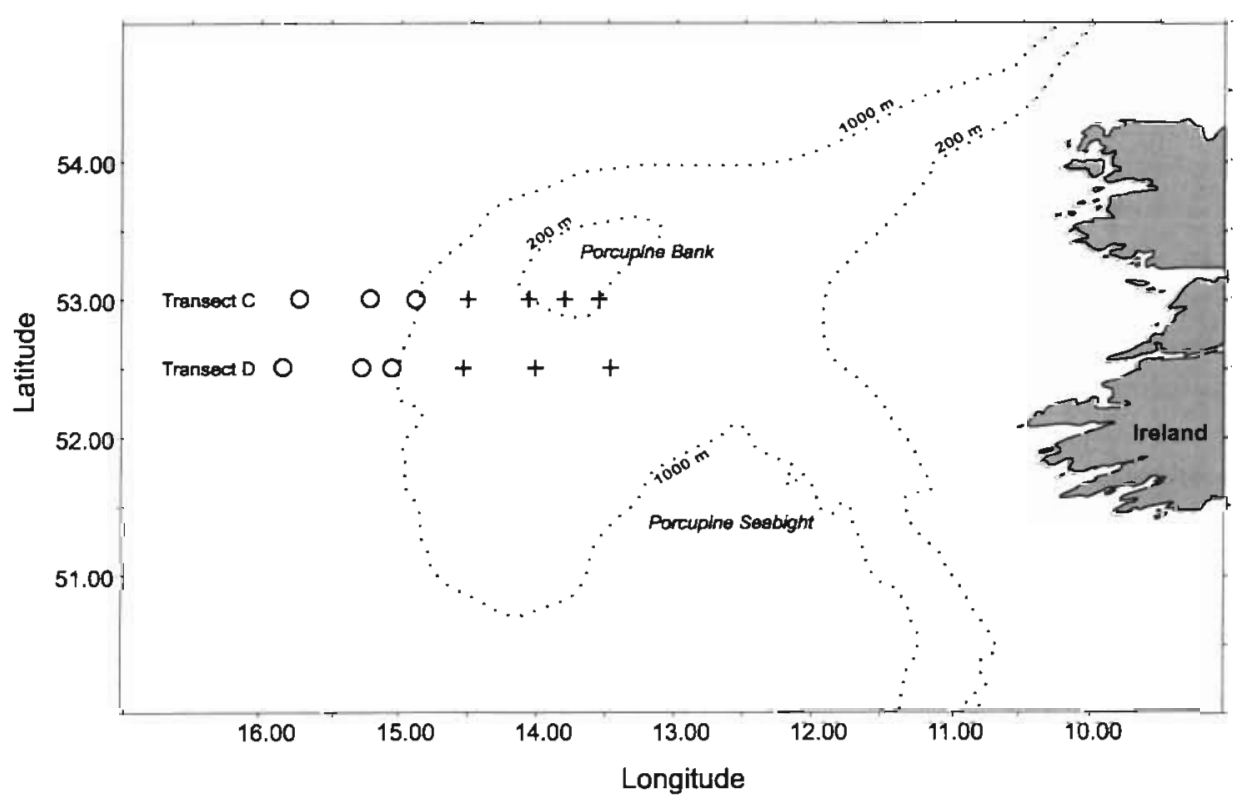

Fig. 1 Location of station grid in March/April 1994 west of Ireland. (O) stations sampled in the secondary shelf edge current, (+) stations sampled above Porcupine Bank 
Table 1. Summary of station information. The 2 sampling areas are distinguished by the water masses: sSEC, secondary shelf edge current; PB, Porcupine Bank; UTC, Universal Time Coordinated

\begin{tabular}{|lcccccr|}
\hline $\begin{array}{l}\text { Tran- } \\
\text { sect }\end{array}$ & Area & Stn & Long. & Lat. & UTC & $\begin{array}{r}\text { Bottom } \\
(\mathrm{m})\end{array}$ \\
\hline C & sSEC & 1 & $53^{\circ} 00.00$ & $15^{\circ} 44.8$ & $13: 18$ & 3244 \\
& SSEC & 2 & $53^{\circ} 00.00$ & $15^{\circ} 14.1$ & $18: 28$ & 2033 \\
& SSEC & 3 & $53^{\circ} 00.00$ & $14^{\circ} 54.9$ & $00: 00$ & 997 \\
& PB & 4 & $53^{\circ} 00.00$ & $14^{\circ} 32.1$ & $04: 45$ & 381 \\
& PB & 5 & $53^{\circ} 00.00$ & $14^{\circ} 05.7$ & $08: 43$ & 205 \\
& PB & 6 & $53^{\circ} 00.00$ & $13^{\circ} 50.0$ & $10: 55$ & 196 \\
& PB & 7 & $53^{\circ} 00.00$ & $13^{\circ} 35.0$ & $03: 12$ & 200 \\
D & SSEC & 8 & $52^{\circ} 30.00$ & $15^{\circ} 51.7$ & $06: 41$ & 3269 \\
& SSEC & 9 & $52^{\circ} 30.00$ & $15^{\circ} 18.1$ & $00: 50$ & 1617 \\
& SSEC & 10 & $52^{\circ} 30.00$ & $15^{\circ} 05.0$ & $20: 42$ & 1026 \\
& PB & 11 & $52^{\circ} 30.00$ & $14^{\circ} 34.0$ & $16: 45$ & 398 \\
& PB & 12 & $52^{\circ} 30.00$ & $14^{\circ} 02.7$ & $13: 01$ & 305 \\
& PB & 13 & $52^{\circ} 30.00$ & $13^{\circ} 29.0$ & 05.03 & 345 \\
\hline
\end{tabular}

Table 2. The sampled depth of the consecutive multiple opening-closing net casts per each station

\begin{tabular}{|lcc|}
\hline Net no. & $\begin{array}{c}\text { Sampled depths } \\
\text { (shallow) }\end{array}$ & $\begin{array}{c}\text { Sampled depths } \\
\text { (deep) }\end{array}$ \\
\hline 1 & $200-150 \mathrm{~m}$ & $650-500 \mathrm{~m}$ \\
2 & $150-100 \mathrm{~m}$ & $300-400 \mathrm{~m}$ \\
3 & $100-50 \mathrm{~m}$ & $400-300 \mathrm{~m}$ \\
4 & $50-25 \mathrm{~m}$ & $300-200 \mathrm{~m}$ \\
5 & $25-0 \mathrm{~m}$ & $200-0 \mathrm{~m}$ \\
\hline
\end{tabular}

assure that both eggs and freshly hatched blue whiting larvae were sampled quantitatively. Kloppmann (1994) evaluated the efficiency of the MCN comparing it with a $60 \mathrm{~cm}$ Bongo net, which is the recommended standard gear for ichthyoplankton sampling (Smith \& Richardson 1977). When properly used, the MCN provides abundance and length frequency data comparable to those collected with a Bongo net.

Two MCN casts per station were conducted to cover the 9 depths sampled (Table 2). After retrieval of the $\mathrm{MCN}$ each net was thoroughly washed, codends were detached and samples rinsed into the relevant sieves. Concentrated samples were preserved in $4 \%$ buffered formalin-seawater solution.

At each station, physical data were recorded to a depth of $1000 \mathrm{~m}$ using a CTD system. The CTD was connected to a rosette sampler, so that microzooplankton samples could be taken simultaneously. Microzooplankton were collected at the midpoint of each shallow MCN interval, namely at 175, 125, 75, 37.5 and $12.5 \mathrm{~m}$, using a rosette sampler equipped with $7.5 \mathrm{l}$ bottles. Water from the bottles was passed through a $45 \mu \mathrm{m}$ sieve. The concentrated samples were pre- served with $4 \%$ buffered formalin-seawater solution. For convenience, we use the term microzooplankton to refer to the zooplankton taxa captured with the method described above. Due to increased swimming speeds, it has to be noted that late-stage copepodites and adult copepods might have escaped capture and their estimated densities are, thus, likely to be underestimated. Also, due to their small size, tintinnids were only partially retained by our sampling and thus excluded from further analysis.

Laboratory analyses. Blue whiting were enumerated and a sub-sample measured to the nearest $0.1 \mathrm{~mm}$ standard length (SL). No correction was made for larval shrinkage due to net-capture damage or preservation.

Microzooplankton from the water bottle samples were identified to the lowest possible taxon and developmental stage, enumerated and measured to the nearest $0.01 \mathrm{~mm}$ using a stereo microscope. Carapace length, total length and width were measured for copepod nauplii, diameter for eggs, metasome length, total length and width for copepodites and adult copepods, and length and width for all other organisms. Using those measurements, wet weight of prey items was calculated (Nishiyama \& Hirano 1983).

For the analysis of feeding habits, larvae were subsampled from 8 size classes $(<3.0,3.0$ to $3.49,3.5$ to $3.99,4.0$ to $4.49,4.5$ to $4.99,5.0$ to $5.49,5.5$ to 5.99 , $\geq 6.0 \mathrm{~mm} \mathrm{SL}$ ). Since blue whiting larvae $>2.6 \mathrm{~mm} \mathrm{SL}$, which had initiated exogenous feeding were observed to be mainly distributed in the upper $100 \mathrm{~m}$ of the water column (Coombs et al. 1981), only larvae from 0 to $100 \mathrm{~m}$ water depth were used for feeding analysis. Each larva was placed on a microscope slide and the entire alimentary canal was excised. The gut was positioned in a drop of glycerin, opened and the contents examined. Each item was identified to the lowest possible taxonomic group and developmental stage, counted and measured, using the same strategy as employed for the water bottle samples.

Data analyses. The abundance of blue whiting larvae was computed as number $1 \mathrm{~m}^{-2}$ sea surface sampled over the upper $650 \mathrm{~m}$ of the water column.

Feeding incidence, the proportion of feeding larvae per station, sampling depth and size class were calculated. Chi-square tests of independence were used to test the null hypotheses that feeding was uniform with respect to station, sampling depth and size of the larvae. The mean number of food items per gut (numerical feeding intensity) and the mean weight of food per gut (weight-based feeding intensity) were calculated using only feeding larvae. The null hypotheses that feeding intensities were evenly distributed were tested with ANOVA. Normality was tested using normal probability plots and Lillefors Test (Daniel 1990). When 
necessary, data were transformed using either a square-root or a Box-Cox power transformation (Sokal \& Rohlf 1981). If significant differences were found, multiple comparison procedures were used to test for pairwise relationships.

The selectivity of fish larvae for their prey was estimated with $\alpha$ (Chesson 1978):

$$
\alpha_{j}=\left(d, / p_{j}\right) /\left(d_{1} / p_{i}\right), \quad \text { for } i=1 \ldots N
$$

where $\mathrm{N}$ is the number of different prey taxa; $d_{j}$ and $p_{j}$ are the proportions of prey $j$ in the diet $(d)$ and in the environment $(p)_{i} d_{i}$ and $p_{i}$ are the same proportions for the $i$ th prey. Chesson's $\alpha$. was first calculated for each larva examined and afterwards averaged for a given length class (Fortier \& Harris 1989). Since the index is independent of fluctuations in the absolute abundance of prey taxa and will only change due to changes in the predators' behavior, it can be averaged and compared between stations and water masses with different absolute prey densities (Chesson 1983).

\section{RESULTS}

\section{Physical environment}

Strong westerly winds averaging 15 to $20 \mathrm{~m} \mathrm{~s}^{-1}$ and wave heights of up to $10 \mathrm{~m}$ prevailed throughout the cruise and prevented stratification of the water column in the euphotic zone. The depth of negligible frictional influence of the wind (Ekman depth) was between 70 and $100 \mathrm{~m}$ (Kloppmann et al. 1999).

Sea surface temperatures in the study area were between 9 and $10^{\circ} \mathrm{C}$. Above the western slope of Porcupine Bank in areas $>1000 \mathrm{~m}$ bottom depth, the surface water was warmer and more saline $\left(\mathrm{T} \leq 10^{\circ} \mathrm{C}\right.$, $\mathrm{S}>35.42$ ), while surface waters above Porcupine Bank were colder and less saline $\left(T<10.0^{\circ} \mathrm{C}, \mathrm{S}<35.40\right)$.

Analysis of the vertical temperature and salinity distributions revealed a core of warm, high-salinity water from the surface to $400 \mathrm{~m}$ depth over the western slope of Porcupine Bank (Fig. 2). Kloppmann et al. (1999) identified the warmer, more saline water mass as North Atlantic Current Water which formed a northward current, termed the SSEC, along the western slope of Porcupine Bank. A frontal zone separated the SSEC from waters above the bank. Above Porcupine Bank a dome of colder and less saline water was detected, indicating an area of upwelling. Kloppmann et al. (1999) concluded that the doming of isolines above the bank was associated with a Taylor column

\section{Blue whiting larvae}

A total of 11953 blue whiting larvae were counted on the 13 stations selected for analyses of feeding,

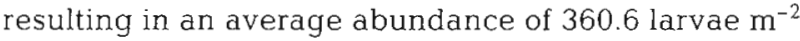
$(\mathrm{SD}=270.2 ;$ median $=327.6 ; \min =24.3 ; \max =731.7)$.
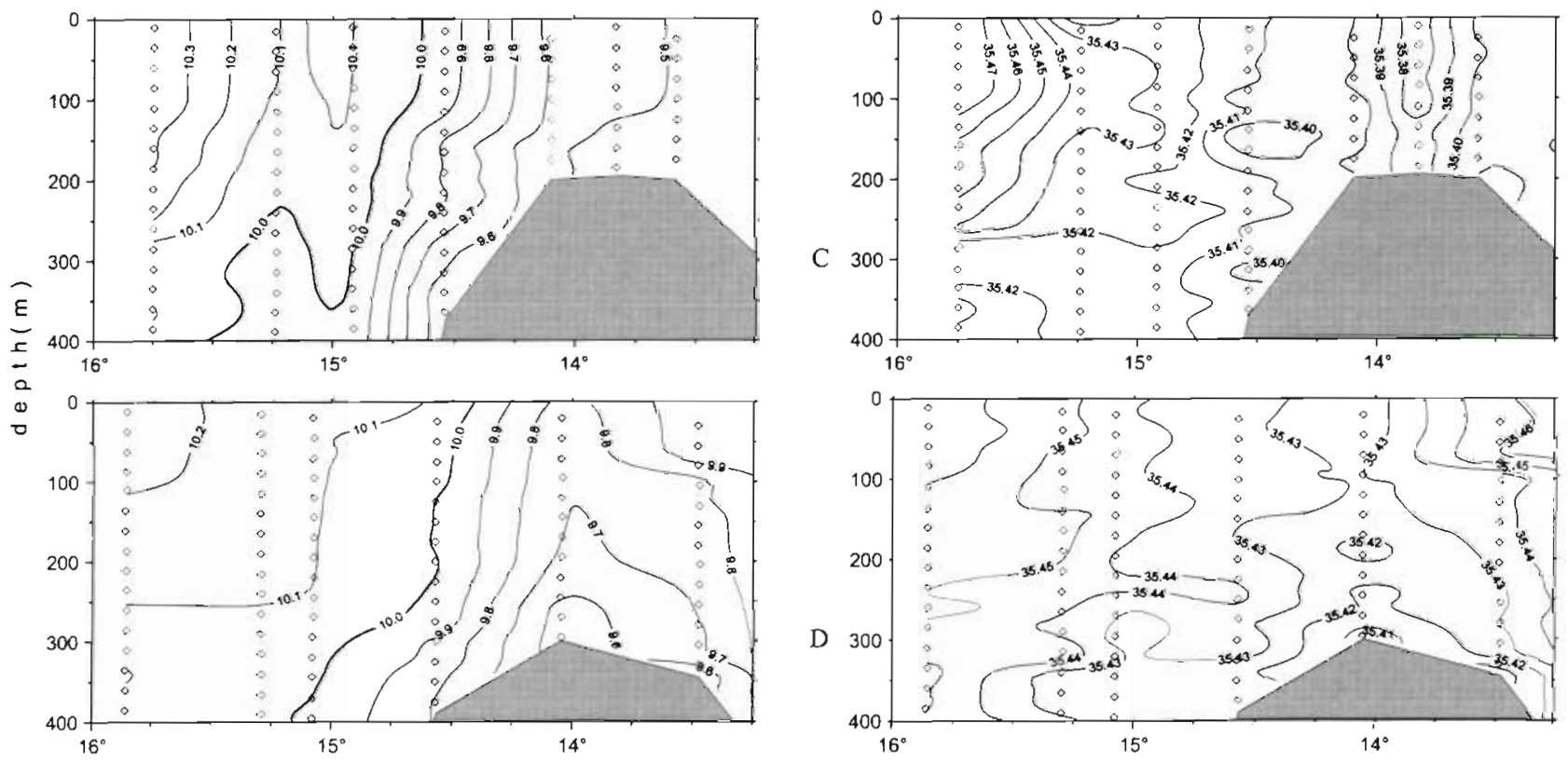

Longitude $W$

Fig. 2. (a) Temperature and (b) salinity distribution in the sampling area. The data grid for computing the isolines was calculated by linear interpolation between the original datapoints. Diamonds show the position of CTD casts 

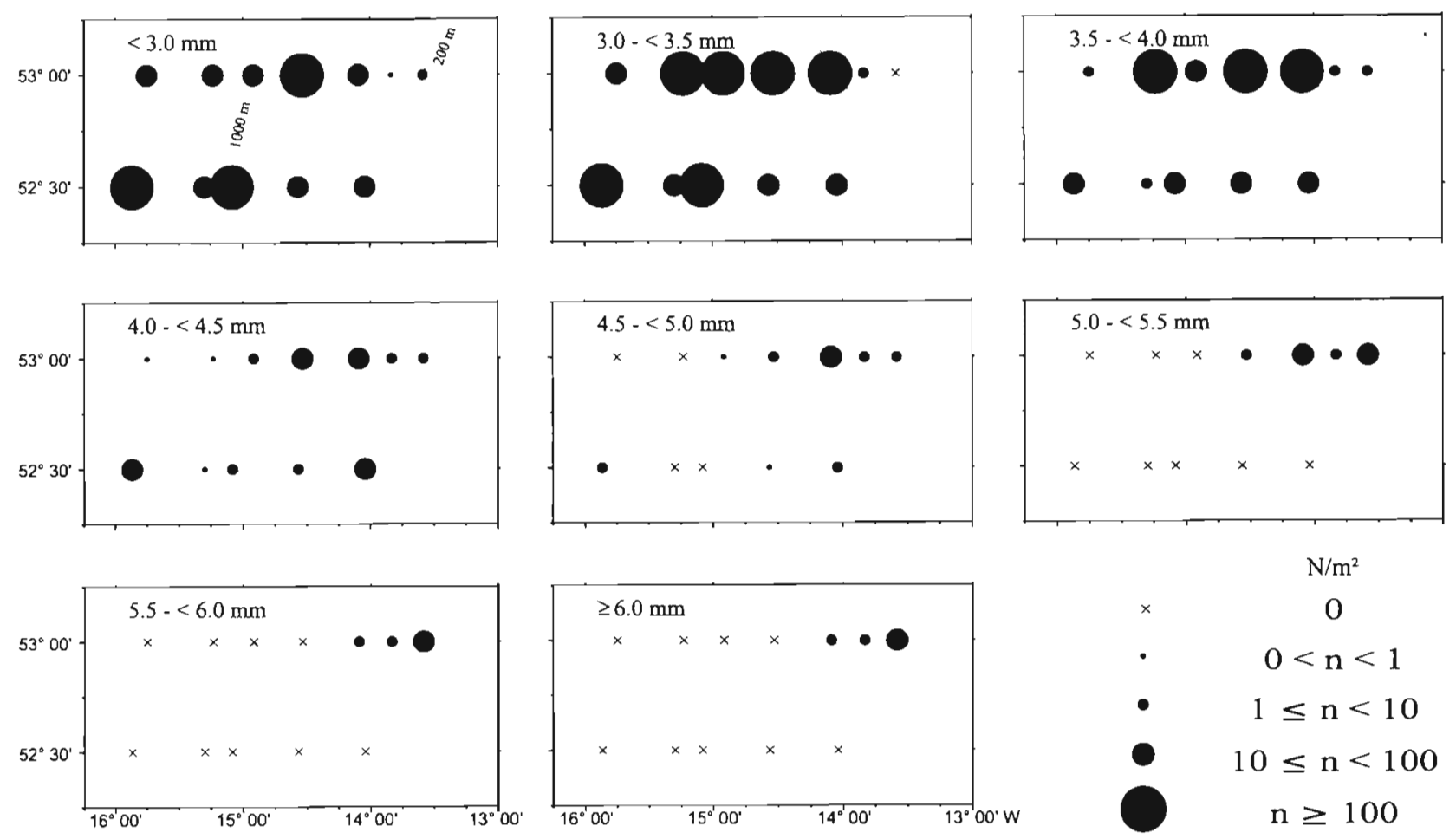

Fig. 3. Abundance of blue whiting larvae by size classes integrated over the upper $650 \mathrm{~m}$ of the water column. (…...) Position of $1000 \mathrm{~m}$ and $200 \mathrm{~m}$ isobaths

Larvae occurred on all stations, with highest concentrations located over depths $>1000 \mathrm{~m}$ and in waters warmer than $10^{\circ} \mathrm{C}$ (Fig. 3). However, these large concentrations were composed almost exclusively of recently hatched larvae $<4 \mathrm{~mm} \mathrm{SL}$. Larvae $>4 \mathrm{~mm} \mathrm{SL}$. were rare in these areas of high abundance. Larger larvae were concentrated in the cooler and less saline waters above Porcupine Bank. Indeed, larvae $>5 \mathrm{~mm}$ SL were found exclusively above Porcupine Bank.

Blue whiting larvae were found in any depth stratum sampled, with modes both in deep and shallow layers (Fig. 4). The deep modes were exclusively attributable to recently hatched larvae, while most feeding larvae were found in the top $100 \mathrm{~m}$ (Kloppmann et al. 1999 and compare Coombs et al. 1981). There were small, nonsignificant changes in vertical distribution between day and night, with larvae being more dispersed at nighttime. However, the vertical resolution of the catches was too coarse to reveal significant diurnal vertical migrations.

\section{Microzooplankton}

A total of 3829 prey items was analyzed. Averaged over all depth and stations, copepod nauplii were the most abundant group, repre- senting $60.0 \%$ of the microzooplankton, followed by copepodite stages $(26.3 \%)$ and adult copepods $(9.9 \%)$. Relatively few free-spawned copepod eggs were collected, amounting to only $3.1 \%$.

In general, naupliar densities were very low, with an overall mean of $5.2 \mathrm{l}^{-1}(\mathrm{SD}=2.75)$. Since naupliar abundance did not change with respect to Transect (ANOVA, $F=0.842, p=0.362$ ), samples from both transects were combined for further analysis. Copepod nauplii were significantly more abundant in the upper $100 \mathrm{~m}$ of the water column (ANOVA, $F=4.07$; $<<0.01$ ),
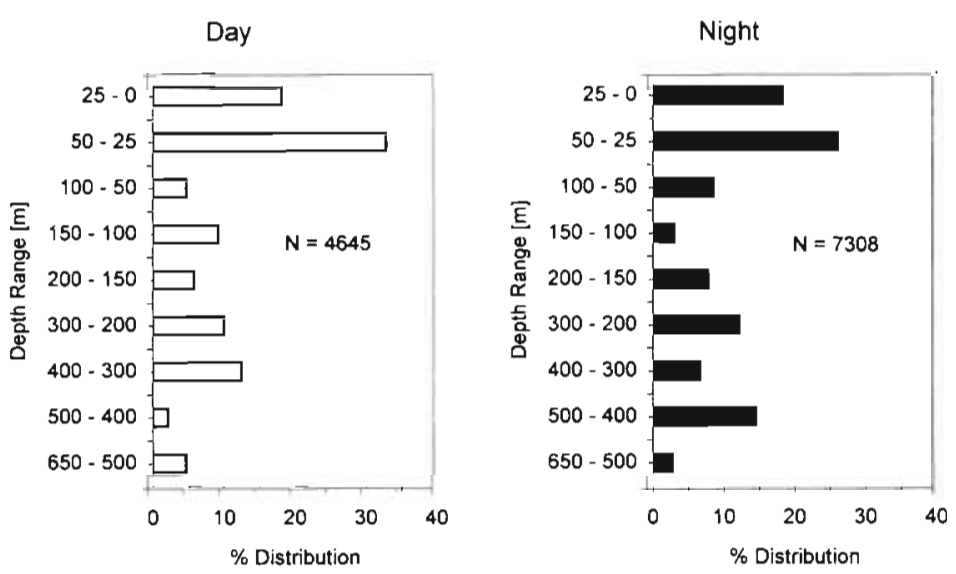

Fig. 4. Vertical distribution of blue whiting larvae during day and night pooled over the 13 stations selected 


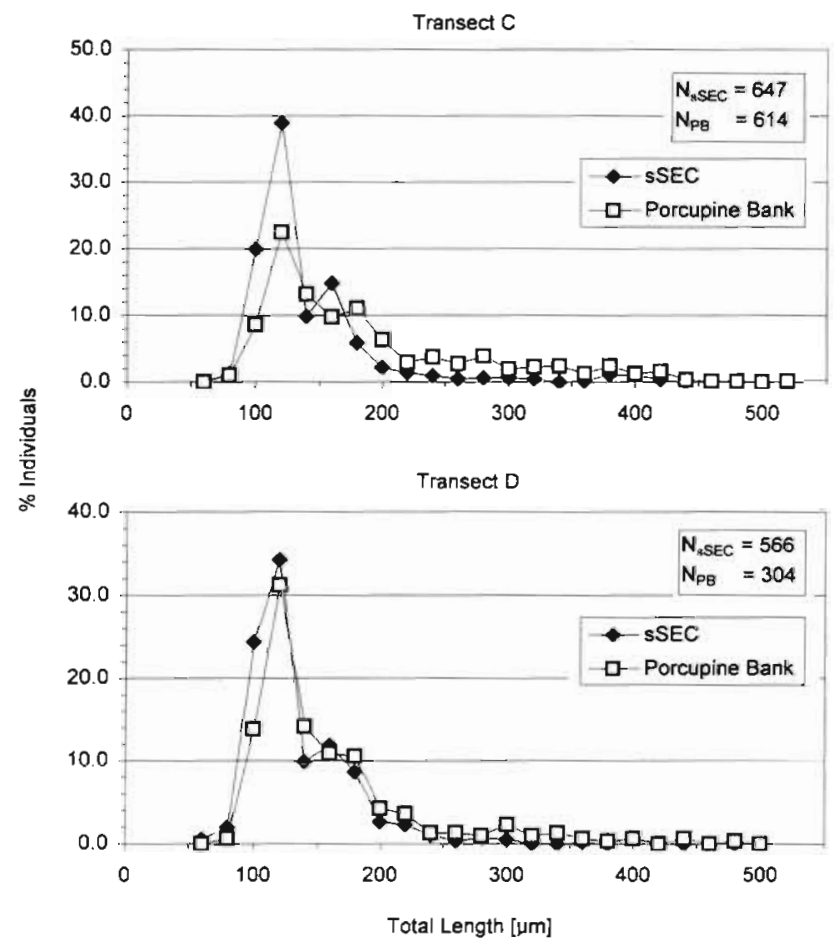

Fig. 5. Length-frequency distribution of copepod nauplii in the waters of the secondary shelf edge current (SSEC) and

Porcupine Bank in the upper $100 \mathrm{~m}$ of the water column

$>200 \mu \mathrm{m}$. The size ranges of naupliar stages of different species overlapped considerably. However, a size frequency distribution for different taxonomic groups revealed that the high abundance of larger nauplii above Porcupine Bank was based predominantly on larger (>200 $\mu \mathrm{m}$ ) calanoid nauplii that were missing in the waters of the shelf edge current.

\section{Larval feeding}

A total of 633 larval blue whiting were analyzed for gut contents. Larval size ranged from 2.5 to $8.4 \mathrm{~mm} \mathrm{SL}$, with the majority in the 3 to $4 \mathrm{~mm}$ SL size class (50\%). Mean feeding incidence for all size classes was $79.6 \%$. No differences in feeding incidence were observed due to larval size class $\left(\chi^{2}=2.375, \mathrm{p}=0.936\right)$. While larval feeding was significantly increased during daylight $\left(\chi^{2}\right.$

the stratum of highest abundance of feeding larvae. Consequently, samples of the upper $100 \mathrm{~m}$ were pooled for further analyses. Significantly higher densities of copepod eggs, nauplii and adults were observed in the waters of the $\mathrm{SSEC}$ than above Porcupine Bank (Table 3).

Nauplii ranged from 60 to $500 \mu \mathrm{m}$ total length, with peak abundance between 100 and $150 \mu \mathrm{m}$ total length. Cumulative frequency distributions of naupliar total length differed significantly between nauplii from the waters of the SSEC and from the waters above Porcupine Bank (Fig. 5). On both transects analyzed, a higher proportion of larger nauplii was found above Porcupine Bank (KS 2 sample, $\mathrm{p} \leq 0.01$ ) (Fig. 5), with additional frequency-peaks in sizes
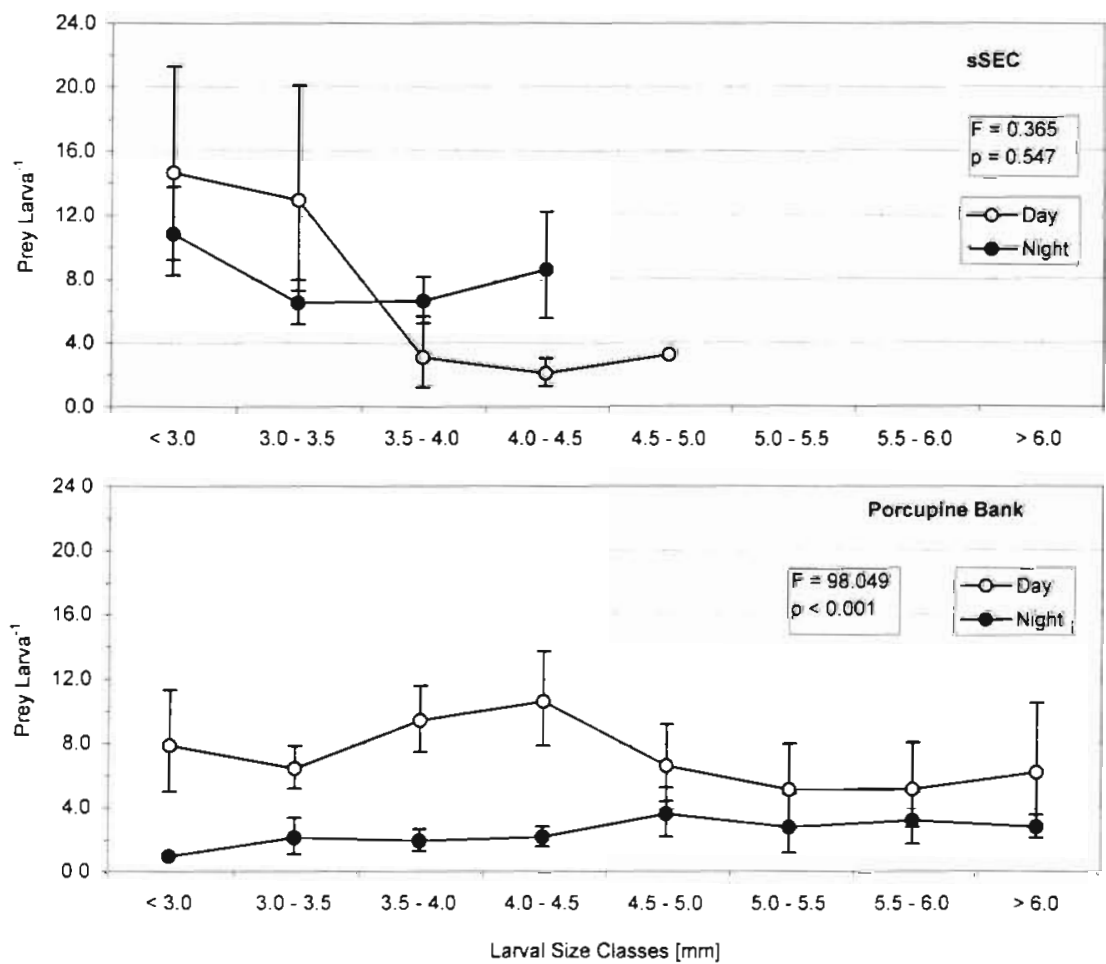

Fig. 6. Comparison of numerical feeding intensities (prey larva ${ }^{-1}$ ) in blue whiting larvae in the waters of the secondary shelf edge current (SSEC) and above Porcupine Bank. Means and confidence intervals are calculated from square-root transformed variates. Values in the table indicate number of fish analyzed

\begin{tabular}{|c|c|c|c|c|c|c|c|c|c|}
\hline \multirow[b]{2}{*}{ SSEC } & \multicolumn{9}{|c|}{ Number of Individuals analyzed } \\
\hline & $<3.0$ & $3.0-3.5$ & $3.5-4.0$ & 4.04 .5 & $4.5-5.0$ & $5.0-5.5$ & $5.5-6.0$ & $>60$ & Total \\
\hline$N_{\text {oery }}$ & 17 & 18 & 13 & 8 & 2 & & & & 58 \\
\hline $\mathrm{N}_{\mathrm{Nppr}}$ & 50 & 56 & 42 & 14 & & & & & 162 \\
\hline $\mathrm{PB}$ & $<3.0$ & $3.0-3.5$ & $3.5-4.0$ & $4.0-4.5$ & $4.5-5.0$ & $5.0-5.5$ & $5.5-6.0$ & $>6.0$ & Total \\
\hline$N_{\text {Day }}$ & 15 & 44 & 39 & 29 & 23 & 14 & 11 & 10 & 185 \\
\hline $\mathbf{N}_{\mathrm{N} p \mathrm{int}}$ & 2 & 13 & 12 & 15 & 16 & 12 & 7 & 22 & 99 \\
\hline
\end{tabular}


Table 3. Results on microzooplankton densities in the upper $100 \mathrm{~m}$ of the water column in the 2 different water masses: sSEC, secondary shelf edge current; $\mathrm{PB}$, Porcupine Bank

\begin{tabular}{|lccl|}
\hline Taxa & \multicolumn{2}{c|}{ Number $\mathrm{l}^{-1}$ (SD) } & Significance \\
& SSEC & PB & \\
\hline Copepod eggs & $0.51(0.47)$ & $0.16(0.21)$ & $\mathrm{p}<0.005$ \\
Copepod nauplii & $7.38(2.78)$ & $5.44(1.69)$ & $\mathrm{p}<0.05$ \\
Copepodites & $1.96(1.02)$ & $1.57(0.70)$ & $\mathrm{p}=0.182$ \\
Adults & $1.63(1.33)$ & $0.89(1.07)$ & $\mathrm{p}<0.01$ \\
\hline
\end{tabular}

$=27.756, \mathrm{p}<0.001 \mathrm{j}$, a high proportion of larvae was observed to continue feeding throughout the night. On both transects sampled, larvae above Porcupine Bank had significantly lower feeding incidences during night than larvae in the shelf edge waters. In addition, blue whiting larvae captured in the sSEC on Transect C were more likely to be feeding than larvae captured above the bank $\left(\chi^{2}=28.0, p<0.001\right)$, while no clear pattern could be established for larvae from Transect D.

There were no differences in numerical feeding intensity (number of prey items ingested) for larvae
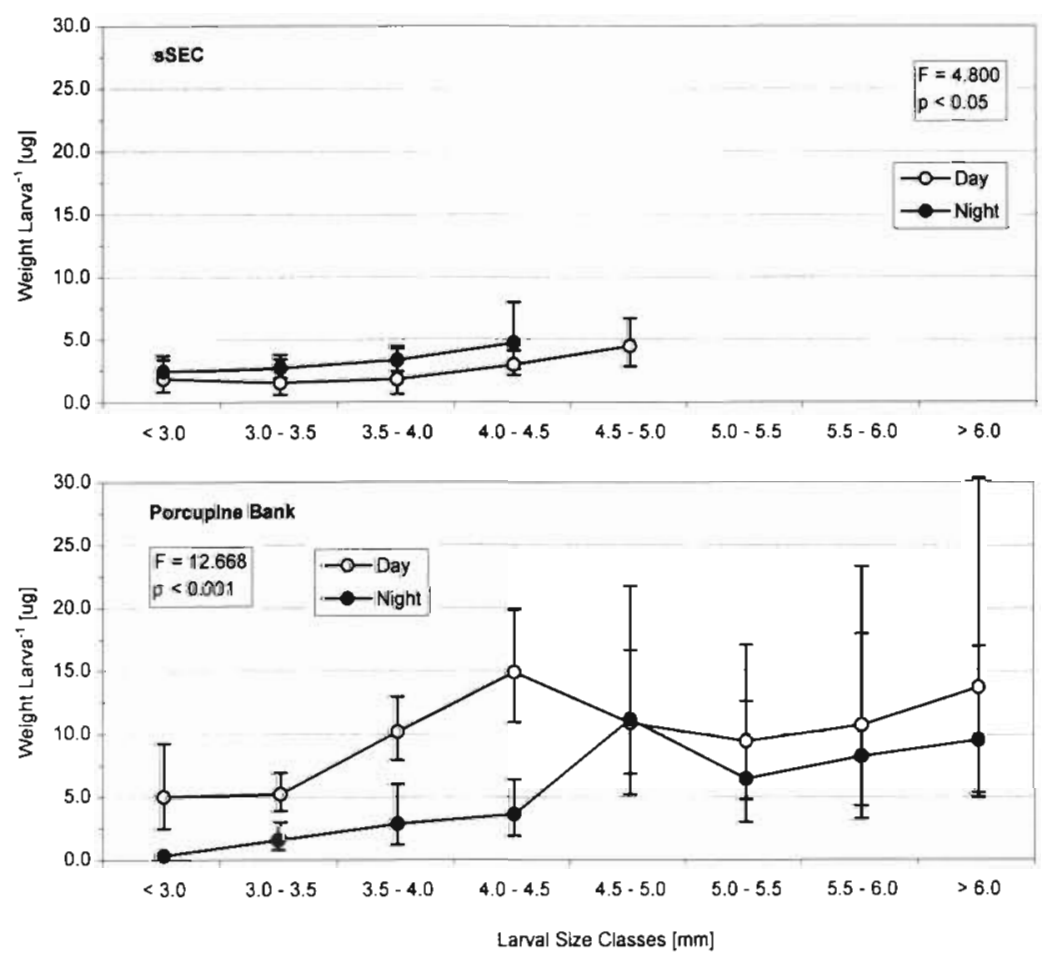

\begin{tabular}{|c|c|c|c|c|c|c|c|c|c|}
\hline \multirow[b]{2}{*}{ SSEC } & \multicolumn{9}{|c|}{ Number of Individuals analyzed } \\
\hline & $<3.0$ & $3,0-35$ & $35-40$ & $4.0-4.5$ & $4.5-5.0$ & $5.0-5.5$ & $55-60$ & $>6.0$ & Total \\
\hline$N_{\text {OAY }}$ & 17 & 18 & 13 & 8 & 2 & & & & 58 \\
\hline$N_{\text {kipp: }}$ & 50 & 56 & 42 & 14 & & & & & 162 \\
\hline $\overrightarrow{P B}$ & $<3.0$ & $3.0-35$ & $3.5-4.0$ & $4.0-4.5$ & $45-50$ & 50.55 & $5.5-6.0$ & $>6.0$ & Total \\
\hline$N_{\text {Dor }}$ & 15 & 44 & 39 & 29 & 23 & 14 & 11 & 10 & 185 \\
\hline$\overline{N_{N p h n}}$ & 2 & 13 & 12 & 15 & 16 & 12 & 7 & 22 & 99 \\
\hline
\end{tabular}

captured from Transect $\mathrm{C}$ or D (ANOVA, $F=0.108, \mathrm{p}=$ 0.743 ), so data were pooled for further analyses. Larvae in the sSEC had ingested significantly more food items than larvae caught above Porcupine Bank (ANOVA, $F=19.115, \mathrm{p}<0.001$ ). While overall larval feeding appeared to be affected by time of day, with higher feeding intensities during daytime, that pattern was only significant for larvae captured above Porcupine Bank (ANOVA, $F=98.049, \mathrm{p}<0.001$ ) and not for larvae in the SSEC (Fig. 6). Larval blue whiting feeding intensity changed significantly with larval size for both larvae sampled above the slope and above the bank. However, the pattern of change was different in the 2 areas (Fig. 6): In the sSEC the highest numbers of prey items were found in first-feeding larvae ( $<3.5 \mathrm{~mm} \mathrm{SL})$, while larvae $>3.5 \mathrm{~mm}$ SL showed very reduced feeding. In comparison, larvae $<3.5 \mathrm{~mm}$ SL above Porcupine Bank had lower feeding intensities and experienced peak feeding intensities at 4 to $4.5 \mathrm{~mm}$ SL.

Feeding intensity by weight revealed no significant difference with respect to Transect (ANOVA, $F=0.066$, $p=0.797$ ), so data from both transects were pooled for all subsequent analyses. Mean weight ingested was significantly higher in larvae sampled above Porcupine Bank (ANOVA, $F=91.247$. $p<0.001$ ) (Fig. 7). There were significant differences for larval size classes 3 to 3.49 , 3.5 to $3.99,4.0$ to $4.49 \mathrm{~mm} \mathrm{SL}$, with up to a 5 -fold increase in gut weight for larvae on the bank as opposed to larvae in the waters of the sSEC. Feeding intensity by weight was affected by time of the day (Fig. 7). Larvae above the bank ingested significantly higher prey weights during daytime (ANOVA, $F=12.668$, p < 0.001), while the opposite was true for larvae in the waters of the SSEC, namely higher feeding intensities at night (ANOVA, $F=4.800, \mathrm{p}<0.05$ ).

Prey length in larval guts ranged from 10 to $1100 \mu \mathrm{m}$. There was a significant increase of mean prey size ingested with increasing larval size $(F=193.595$, $\mathrm{p}<0.001$ ). Blue whiting larvae of all size classes fed on significantly larger organ-

Fig. 7. Comparison of weight-based feeding intensities (weight larva-1) in blue whiting larvae in the waters of the secondary shelf edge current (sSEC) and above Porcupine Bank. Means and confidence intervals are calculated from Box-Cox transformed variates. Values in the table indicate number of fish analyzed 

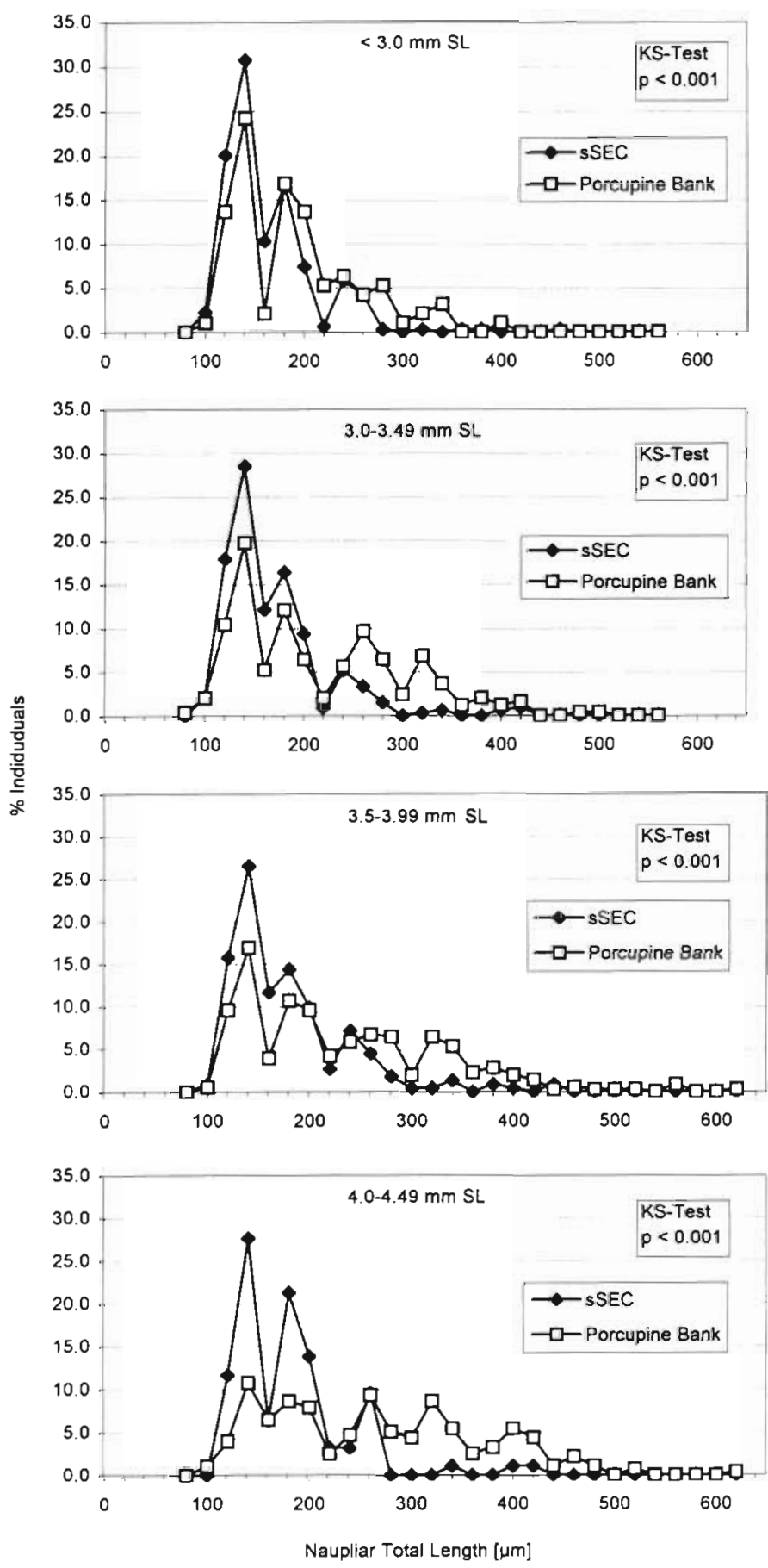

Fig. 8. Comparison of prey length ingested by larval blue whiting in the waters of the secondary shelf edge current (sSEC) and above Porcupine Bank

isms above Porcupine Bank than in the waters of the sSEC. The observed difference was significant for all developmental stages of copepods, that is to say, for free-spawned eggs (ANOVA, $F=8.955, p<0.005$ ), copepod nauplii (ANOVA, $F=522.213$, $p<0.001$ ) and for copepodites and adult copepods (ANOVA, $F=$
5.847, $\mathrm{p}<0.05)$. However, the size difference was most pronounced for copepod nauplii. Above Porcupine Bank, larvae $<4.5 \mathrm{~mm}$ SL ingested significantly more larger nauplii than their counterparts in the waters of the SSEC (Fig. 8).

At all sizes, blue whiting larvae preyed primarily on developmental stages of copepods (Fig. 9). However, first-feeding larvae also ingested high numbers of tintinnids. This was especially true for first-feeding larvae from the sSEC, whose diet consisted numerically of more than $50 \%$ of tintinnids. With increasing larval size, blue whiting larvae tended to prey on progressively larger items, shifting from protozoans to nauplii, then to copepodite stages and adult copepods.

Size distributions of copepod nauplii in the larval guts were significantly different from those in the water column (Fig. 10) insofar as larvae tended to ingest proportionally more, larger nauplii. While those differences were less striking in the waters of the sSEC, they were very pronounced for larvae feeding above Porcupine Bank. In addition to cyclopoid nauplii (100 to $200 \mu \mathrm{m}$ ), Porcupine Bank larvae ingested a higher abundance of calanoid nauplii as was revealed by additional peaks in the size-frequency distribution (>200 $\mu$ m total length).

Proportional abundance of copepodite stages and adult copepods could not be estimated without bias, due to sampling gear bias, and were thus excluded from the analysis of prey preference. Blue whiting larvae in the SSEC showed high preference for cyclopoid nauplii in all larval stages analyzed, but very little selection for other groups (Table 4). In contrast, only the youngest larval stages $(<4.0 \mathrm{~mm} \mathrm{SL})$ selected for cyclopoid nauplii above Porcupine Bank, while calanoid nauplii were preferred by blue whiting of all sizes analyzed. In addition, there was a strong preference for free-spawned copepod eggs.

\section{DISCUSSION}

Seasonal occurrence, abundance, horizontal and vertical distribution of blue whiting larvae in relation to hydrographic and biological conditions

Bainbridge \& Cooper (1973) suggested that blue whiting increase the survival of their offspring by synchronizing larval hatching with maximum annual availability of their prey, thus following the predictions of the match-mismatch hypothesis (Cushing 1975). However, this 'synchronous' strategy seems very unlikely for blue whiting of the Porcupine Bank area, since highest concentrations of blue whiting larvae are consistently observed in early April $1 \mathrm{O}^{\prime}$ Brien \& Fives 1995), while primary and secondary productivity peaks 

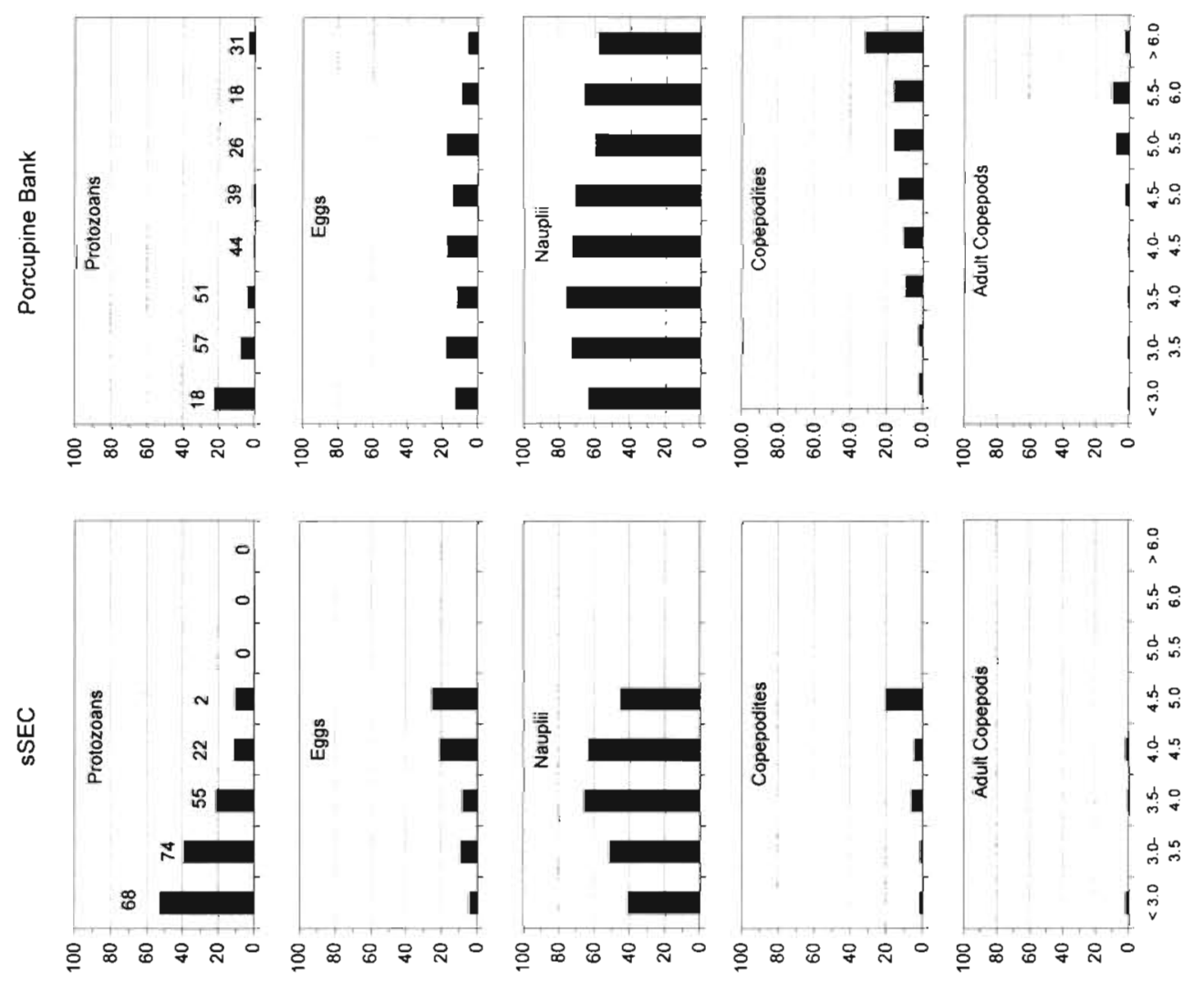

o JaqunN \%
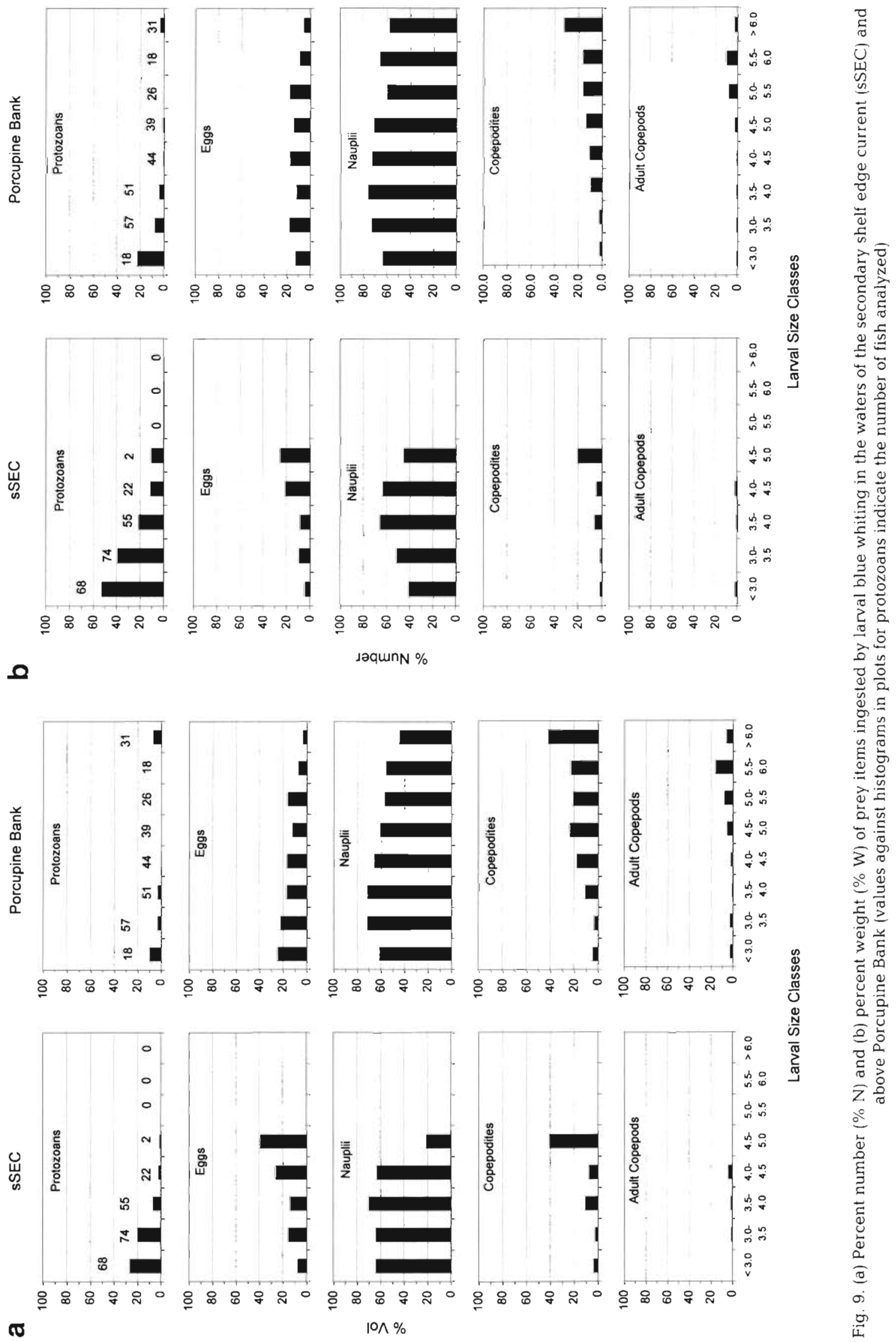


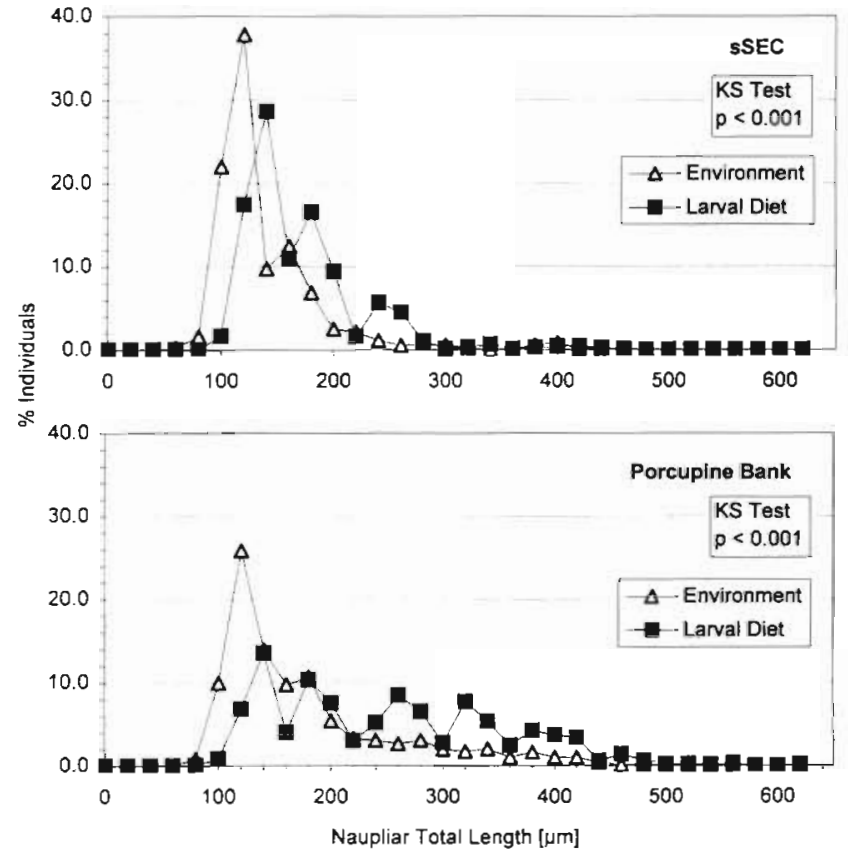

Fig. 10. Naupliar total length in the water column and the diet of blue whiting larvae in the waters of the secondary shelf edge current (SSEC) and above Porcupine Bank

in May (Colebrook 1986). During our sampling in 1994 , blue whiting larvae occurred at a time when the water column was still thermally unstratified, indicating that spring bloom had not yet commenced. This was supported by low concentrations of copepod nauplii, with cyclopoid nauplii, namely Oithonidae, contributing most to their number As Oithonidae are known to maintain populations under more severe conditions and contribute relatively more to copepod biomass in fall and winter (Sabatini \& Kiørboe 1994), their dominance in the waters both off and on the bank was another indication that spring bloom and secondary production had yet to start. Blue whiting spawning occurs all along the European shelf edge, reaching as far north as to the west of Norway. While spawning in the more northern habitats is initiated later in the year, the pattern observed for blue whiting in the Porcupine Bank area still holds, namely onset of hatching prior to spring bloom and peak secondary productivity. Blue whiting might thus be best described as 'early' strategists (Fortier et al. 1995) that produce larvae that initiate feeding weeks before the maximum abundance of potential prey. Similar observations were made for Arctic cod Boreogadus saida and sand lance Ammodytes sp. larvae in Hudson Bay (Fortier et al. 1995) and for larval Pacific sand lance Ammodytes hexapterus and rock sole Pleuronectes bilineatus in Auke Bay, Alaska (Haldorson et al. 1993). Bollens et al. (1992) suggested that 'early' strategists may take advantage of 2 possible mechanisms, namely avoidance of predators due to the early time of hatching and matching of late larval and early juvenile stages with peak abundance of zooplankton in summer.

In 1980 and 1983, at the time of their peak abundance, blue whiting larvae accounted for more than $80 \%$ of the ichtyoplankton in the area of Porcupine Bank, sampled to a maximum depth of $200 \mathrm{~m}$, varying according to bottom depth (O'Brien \& Fives 1995). Our observations were similar, as blue whiting larvae comprised $81 \%$ of all fish larvae at the time of our sampling in 1994. Thus, in addition to avoiding extra predation pressure, initiating feeding at a time prior to zooplankton maximum abundance may reduce inter-specific competition for prey. Blue whiting larvae might well be able to successfully initiate feeding at the observed low concentrations of potential prey organisms while at the same time avoiding predation pressure and competition for the admittedly scarce resource. Prey concen-

Table 4. Mean prey preference of blue whiting larvae in the waters of the secondary shelf edge current, and above Porcupine Bank, with preference indicated

\begin{tabular}{|c|c|c|c|c|c|c|c|c|}
\hline & \multicolumn{8}{|c|}{ Larval length classes (mm) } \\
\hline & $<3.0$ & $3.0-3.5$ & $3.5-4.0$ & $4.0-4.5$ & $4.5-5.0$ & $5.0-5.5$ & $5.5-6.0$ & $>6.0$ \\
\hline \multicolumn{9}{|c|}{ Secondary shelf edge current } \\
\hline No. of larvae & 60 & 64 & 52 & 22 & 2 & 0 & 0 & 0 \\
\hline Eggs & 0.08 & 0.21 & 0.17 & $0.28^{\circ}$ & & & & \\
\hline Cyclopoid nauplii & $0.57^{\circ}$ & $0.48^{\circ}$ & $0.46^{\circ}$ & $0.40^{\circ}$ & & & & \\
\hline Calanoid nauplii & 0.16 & 0.19 & 0.20 & 0.20 & & & & \\
\hline Other nauplii & 0.20 & 0.19 & 0.24 & 0.18 & & & & \\
\hline \multicolumn{9}{|l|}{ Porcupine Bank } \\
\hline No. of larvae & 16 & 56 & 48 & 43 & 39 & 24 & 18 & 27 \\
\hline Eggs & 0.00 & $0.34^{\circ}$ & 0.17 & $0,45^{\circ}$ & $0.34^{\circ}$ & $0.40^{\circ}$ & $0.29^{\circ}$ & 0.00 \\
\hline Cyclopoid nauplii & $0.26^{\circ}$ & $0.35^{\circ}$ & $0.31^{\circ}$ & 0.16 & 0.18 & 0.06 & 0.06 & 0.10 \\
\hline Calanoid nauplii & $0.61^{\circ}$ & $0.42^{\circ}$ & $0.53^{\circ}$ & $0.63^{\circ}$ & $0.62^{\circ}$ & $0.66^{\circ}$ & $0.78^{\circ}$ & $0.58^{\circ}$ \\
\hline Other nauplii & 0.07 & 0.07 & 0.10 & 0.04 & 0.12 & 0.13 & 0.00 & $0.34^{\circ}$ \\
\hline
\end{tabular}


trations like those observed in our study have recently been documented to be adequate for marine fish larvae to successfully initiate feeding (Paul 1983, Munk 1995). Larvae apparently adjust their behavior in relation to the prey environment, namely by increasing search activity and decreasing prey selectivity when prey is scarce.

The distribution of the separate length classes of blue whiting larvae during this study suggests a geographic shift during larval development from off the bank toward it. Kloppmann et al. (1999) concluded that larvae hatching at the western periphery of Porcupine Bank are advected towards the central parts of the bank and retained there by a Taylor column circulation. Retention and aggregation of blue whiting larvae by Taylor column might thus facilitate the existence of a separate spawning population on Porcupine Bank. Similar conditions have been described for Flemish Cap redfish and cod (Kudlo \& Boytsov 1979, Anderson 1984) and Rockall Bank haddock (Dooley 1984 cf. Bakun 1996).

\section{Feeding conditions and success of blue whiting larvae in the waters of the secondary shelf edge current and above Porcupine Bank}

Throughout our sampling grid, densities of appropriate prey for blue whiting larvae, namely copepod eggs and nauplii (Conway 1980, Hillgruber et al. 1997), were extremely low, with mean values of 6.3 nauplii $1^{-1}$ and 0.3 free-spawned eggs $\mathrm{l}^{-1}$ in the upper $100 \mathrm{~m}$ of the water column (Table 2). The low number of freespawned eggs concurs with our observation that the majority of the nauplii could be attributed to egg-sac carrying Oithonidae. Oithonidae, which carry eggsacs, are considered to be anatomically less specialized than calanoid copepods and able to maintain an almost constant weight-specific egg production throughout the year (Sabatini \& Kiørboe 1994). In contrast, freespawning calanoid copepods show a very strong seasonal signal, suggesting that at the time of sampling egg production for calanoid copepods had not reached its maximum.

Nauplii were more abundant in the sSEC than in the bank area. However, analyses of their size composition revealed that though more plentiful, there were proportionally more, smaller nauplii off the bank in the waters of the sSEC. In comparison, nauplii above Porcupine Bank were fewer but proportionally larger. While Taylor column circulations have been suggested to enhance zooplankton production above seamounts, evidence concerning densities is often conflicting. Boehlert \& Genin (1987) suggested that instead of considering zooplankton biomass it might be more reveal- ing to analyze specific taxa and their abundance and presence/absence above topographic structures. Our results demonstrate that the Porcupine Bank area differed in species composition compared to the waters of the sSEC. Large calanoid nauplii were present above the bank but lacking in the SSEC, i.e. virtually no nauplii of the species Calanus sp. were observed in the sSEC, while they occurred consistently above Porcupine Bank. Similar results have been documented of the shallow banks off Nova Scotia, where in early spring Calanus sp. and Pseudocalanus sp. copepods were dominant (O'Boyle et al. 1984).

In April 1995, White et al (1998) observed the same doming of isothermals above Porcupine Bank as was described in our study. In addition, some surface reduction in inorganic nutrient values was observed above Porcupine Bank but not in the waters of the sSEC, indicating the onset of spring bloom above the bank. Differences in primary productivity might translate into differences in secondary productivity and, thus, be responsible for the occurrence of proportionally more large calanoid nauplii above Porcupine Bank in comparison to the sSEC.

In spite of very low naupliar densities, a high proportion of blue whiting larvae successfully initiated feeding. Daytime feeding incidences were even higher than those reported for blue whiting larvae of the Rockall Bank area (Conway 1980), suggesting that larvae are capable of successfully feeding at the low prey densities reported here.

Concurrent with higher densities of prey items, blue whiting larvae in the waters of the SSEC had higher feeding incidences and higher numerical feeding intensities than larvae of comparable size classes above the bank. This result could suggest that the water mass above the western slope of the bank provided a better feeding environment for first-feeding larvae. However, both feeding incidence and numerical feeding intensity proved to be potentially misleading and provided only an indication of larval feeding success. First-feeding blue whiting larvae in the waters of the sSEC preyed heavily on tintinnids and small cyclopoid nauplii. Thus, despite ingesting large numbers, their gut weight and thus energetic gain was lower than that of larvae above Porcupine Bank, which fed on fewer but relatively larger organisms.

Differences between the foraging patterns of blue whiting larvae in the 2 rearing habitats were also manifested in the apparent selection of prey items. Larvae in the sSEC ingested proportionally more cyclopoid nauplii and never selected for calanoid nauplii, probably because of their apparent rareness. In comparison, larvae of all size classes analyzed above Porcupine Bank showed a strong selection for calanoid nauplii. Selection for calanoid nauplii and against cyclopoid 
nauplii has been reported for many different larval species and suggestions have been made that behavioral differences of the nauplii might result in differences of prey perception by the larvae, and thus lead to different capture probabilities (Hillgruber et al. 1995, Pepin \& Penney 1997). Pepin \& Penney (1997) also noted that prey selection could differ substantially among larval species. However, in this study blue whiting larvae showed intra-specific selection patterns, which differed depending on the habitat in which they were reared.

The main objective of our study was to analyze the different rearing environments of blue whiting larvae and to determine if larvae in the retention area above Porcupine Bank encountered feeding conditions that secure their survival while being retained there. While superficially it seemed that larvae in the sSEC were finding better feeding conditions, as indicated by higher naupliar counts in the environment, higher feeding incidences, and numerical feeding intensities, a more in-depth analysis revealed that the opposite was true, namely that entrainment above Porcupine Bank was energetically beneficial. In agreement with the model-based approach by Werner et al. (1996), we conclude that retention of blue whiting larvae above Porcupine Bank not only ensures their population integrity but also provides the larvae with a beneficial feeding environment to sustain their survival.

\section{CONCLUSIONS}

(1) Blue whiting of the Porcupine Bank assemblage spawn well ahead of the spring bloom, thus applying an 'early' strategy for their offspring.

(2) Numerical feeding intensities provide only an indication for larval feeding conditions and are potentially misleading when larvae are feeding on different taxonomic groups of differing sizes.

(3) Likely retention of blue whiting larvae above Porcupine Bank may not only provide a means of maintaining larval distributions but also of supporting larval survival by supplying enhanced feeding conditions.

Acknowledgements. This study was funded as part of the EU/AIR grant no. AIR2-CT93-1105. We particularly want to thank captain and crew of RV 'Heincke' for their valuable support at sea. We are grateful to K. Barz, M. Bomplitz, A. Castello, S. Grabbert, H. Keuthen, Ö. Kocoglu, N. Raethke, J. Wohlfart and $B$. Wurche for their assistance in the laboratory and in the field. Dr H. von Westernhagen, Dr D. Klumpp and Prof. Dr W. Nellen, as well as 3 anonymous referees provided helpful reviews. This article is based in part on a doctoral study by $\mathrm{NH}$ in the Faculty of Biology, University of Hamburg. NH was supported by a graduate scholarship provided by the 'Biologische Anstalt Helgoland', Germany.

\section{LITERATURE CITED}

Anderson JT (1984) Early life history of redfish (Sebastes spp.) on Flemish Cap. Can J Fish Aquat Sci 41:1106-1116

Bailey K, Spring S (1992) Comparison of larval, age-0 juvenile and age- 2 recruit abundance indices of walleye pollock, Theragra chalcogramma, in the western Gulf of Alaska. ICES J Mar Sci 49:297-304

Bailey RS (1982) The population biology of blue whiting in the North Atlantic. Adv Mar Biol 19:257-355

Bainbridge V. Cooper GA (1973) The distribution and abundance of the larvae of blue whiting. Micromesistius poutassou (Risso), in the north-east Atlantic 1948-1970. Bull Mar Ecol 8:99-114

Bakun A (1996) Patterns in the Ocean. Ocean processes and marine population dynamics. California Sea Grant College System, National Oceanic and Atmospheric Administration in cooperation with Centro de Investigaciones Biológicas del Noroeste, La Paz, BCS México

Boehlert GW, Genin A (1987) A review of the effects of seamounts on biological processes. In: Keating BH, Fryer P, Batiza R, Boehlert GW (eds) Seamounts and atolls. Geophys Monogr 43:319-334

Bollens SM, Frost BW, Schaninger HR, Davis CS, Way KJ, Landsteiner MC (1992) Seasonal plankton cycles in a temperate fjord and comments on the match-mismatch hypothesis. J Plankton Res 14(9): 1279-1305

Chesson J (1978) Measuring preference in selective predation. Ecology 59:211-215

Chesson J (1983) The estimation and analysis of preference and its relationship to foraging models. Ecology 64(5): $1297-1304$

Colebrook JM (1986) Continuous plankton records: the distribution and standing crop of the plankton of the shelf and ocean to the west of the British Isles. Proc R Soc Edinb 88B:221-237

Conway DVP (1980) The food of larval blue whiting, Micromesistius poutassou (Risso), in the Rockall area. J Fish Biol 16:709-723

Coombs SH, Pipe RK, Mitchell CE (1981) The vertical distribution of eggs and larvae of blue whiting (Micromesistius poutassou) and mackerel (Scomber scombrus) in the eastern North Atlantic and North Sea. Rapp P-V Reun Cons Int Explor Mer 178:188-195

Cushing DH (1975) Marine ecology and fisheries. Cambridge University Press, London

Daniel WW (1990) Applied nonparametric statistics. PWSKent, Boston

Fortier L, Harris RP (1989) Optimal foraging and densitydependent competition in marine fish larvae. Mar Ecol Prog Ser 51:19-33

Fortier L, Ponton D, Gilbert M (1995) The match/mismatch hypothesis and the feeding success of fish larvae in icecovered southeastern Hudson Bay. Mar Ecol Prog Ser 120 $11-27$

Haldorson L, Pritchett M, Sterritt D, Watts J (1993) Abundance of marine fish larvae during spring in a southeastern Alaskan bay. Fish Bull US 91:36-44

Hillgruber N, Haldorson LJ, Paul AJ (1995) Feeding selectivity of larval walleye pollock Theragra chalcogramma in the oceanic domain of the Bering Sea. Mar Ecol Prog Ser 120:1-10

Hillgruber $N$, Kloppmann $M$, Wahl $E$, von Westernhagen $H$ (1997) Feeding of larval blue whiting and Atlantic mackerel: a comparison of foraging strategies. J Fish Biol 51 (Suppl A):230-249

Houde ED (1987) Fish early dynamics and recruitment vari- 
ability. Am Fish Soc Symp 2:17-29

Iles TD, Sinclair M (1982) Atlantic herring: stock discreteness and abundance. Science 215:627-633

Kloppmann M (1994). Kleinskalige Vertikalverteilungen von Fischlarven bei Helgoland. University of Hamburg

Kloppmann M, Mohn C, Bartsch J (1999) The distribution of blue whiting eggs and larvae on Porcupine Bank in relation to hydrography and currents. Fish Res (in press)

Kudlo BP, Boytsov VD (1979) The effect of water dynamics on year class strength of cod on Flemish Cap. ICNAF Sel Pap $5: 7-9$

McLaren IA, AvendaVD (1979) The effect of water dynamics on year class strength of cod on Flemish Cap. ICNAF Sel Pap 5:7-9

Munk P (1995) Foraging behaviour of larval cod (Gadus morhua) influenced by prey density and hunger. Mar Biol 122:205-2:12

Nishiyama T, Hirano K (1983) Estimation of zooplankton weight in the gut of larval walleye pollock (Theragra chalcogramma). Bull Plankton Soc Jpn 30(2):159-170

O'Boyle RN, Sinclair M, Conover RJ, Mann KH, Kohler AC (1984) Temporal and spatial distribution of ichthyoplankton communities of the Scotian Shelf in relation to biological, hydrological, and physiographic features. Rapp P-V Reun Cons Int Explor Mer 183:27-40

Editorial responsibility: Otto Kinne (Editor),

Oldendorf/Luhe, Germany
O'Brien B, Fives JM (1995) Ichthyoplankton distribution and abundance off the west coast of Ireland. ICES J Mar Sci 52:233-245

Paul AJ (1983) Light, temperature, nauplii concentration, and prey capture by first feeding pollock larvae Theragra chalcogramma. Mar Ecol Prog Ser 13:175-179

Pepin P. Penney RW (1997) Patterns of prey size and taxonomic composition in larval fish: are there general size dependent models. J Fish Biol 53 (Suppl A):84-100

Proudman $J$ (1916) On the motion of solids in a liquid possessing vorticity. Proc R Soc A 92:400-424

Sabatini M, Kiørboe T (1994) Egg production, growth and development of the cyclopoid copepod Oithona similis. J Plankton Res 16(10):1329-1351

Smith PE, Richardson SL (1977) Standard techniques for pelagic fish egg and larva survey. FAO Fish Tech Pap 175

Sokal RS, Rohlf FJ (1981) Biometry, 2nd edn. Freeman, San Francisco

Taylor GI (1917) Motion of solids in fluids when the flow is not irrotational. Proc R Soc A 93:99-113

Werner FE, Perry RI, Lough RG, Naimie CE (1996) Trophodynamic and advective influences on Georges Bank larval cod and haddock. Deep-Sea Res II 43(7-8):1793-1822

White M, Mohn C, Orren MJ (1998). Nutrient distribution across the Porcupine Bank. ICES J Mar Sci 55:1082-1094

Submitted: November 11, 1998; Accepted: May 7, 1999

Proots received from author(s): October 8, 1999 